\title{
Individual variability in trophic position and diet of a marine omnivore is linked to kelp bed habitat
}

\author{
Lucy Jack*, Stephen R. Wing \\ Department of Marine Science, University of Otago, 310 Castle Street, Dunedin 9054, New Zealand
}

\begin{abstract}
Omnivores play an important role in the routing and distribution of organic matter across food webs. We demonstrate a novel approach to quantifying the coincidence of landscapescale nutritional gradients with niche breadth in terms of variability in trophic level and use of basal organic matter sources. We provide an example of the links between individual variability in resource use and habitat of a broad-spectrum omnivore, the red rock lobster Jasus edwardsii. Information on the co-occurrence of $J$. edwardsii with kelp bed habitats Ecklonia radiata and with their preferred prey Mytilus edulis galloprovinciallis were collected at 60 sites across Fiordland, southwest New Zealand. Analysis of distance-based linear models (DISTLM) indicated that the presence of mussels was the best predictor of lobster occurrence in the model set. At a subset of sites, we collected lobster muscle for stable isotope analysis and measured 3 demographic parameters from the lobsters: relative abundance, sex and carapace lengths. We characterised habitats with surveys of common kelp and mussels. Using stable isotope signatures $\left(\delta^{13} \mathrm{C}\right.$ and $\left.\delta^{15} \mathrm{~N}\right)$, we calculated individual-based estimates of trophic level and the mixture of organic matter sources, i.e. phytoplankton and macroalgae. Using DISTLM, lobster and mussel densities best explained variability in lobster diet. Variability in resource use was distinct inside and outside of kelp bed habitat. In kelp beds, lobsters fed at a higher average trophic level, with low variability among individuals in trophic level and use of organic matter sources. Outside kelp beds, individual variability indicated broad trophic diversification. These patterns indicate a strong influence of the nutritional landscape at the scale of the metapopulation, which has important implications for understanding dietary influences on population structure.
\end{abstract}

KEY WORDS: Food web · Omnivory $\cdot$ Stable isotopes $\cdot$ Jasus edwardsii $\cdot$ Kelp forest

\section{INTRODUCTION}

Spatial heterogeneity in the quality and quantity of food and the resulting diversity of exploitative strategies has important consequences for the distribution of organic matter within food webs, the food web stability and the subsequent stability of populations they support (Huxel et al. 2004). Recent evidence that much of the observed diversity in resource use occurs at the individual level has led investigators to re-examine the basis for niche width variation and trophic dynamics in natural populations (Bolnick et al. 2003).
Individual variability in diet has been widely observed in aquatic systems and is particularly apparent in upper trophic level consumers. For example, evidence for long-term individual specialisation has been observed in sea otters (Newsome et al. 2009), pinnipeds (Arnould et al. 2011) and sea turtles (Vander Zanden et al. 2010), where isotopic time-series measured within individuals indicated consistent differences in diet. These observations correspond to the within-individual component of variability of niche width (WIC, sensu Bolnick et al. 2003). In addition, the level of variability between individuals can also be found to differ among sub-populations. This 
between-individual component (BIC) of niche width can be quantified as the high variance in isotopic signatures, indicative of large differences in feeding behaviour among individuals in a population (Fry et al. 1999). Variability in the composition of prey at higher trophic levels can influence the relative use of basal organic matter sources. Thus both within- and between-individual variability may drive access to a broader base of organic matter sources in food webs. In the present study, we investigate the level of variability between individuals in multiple subpopulations of a marine omnivore.

A simple, important structural feature of food web ecology is that increases in diversity within guilds of primary producers lead to stability in the total source pool of organic matter available to food webs (Tilman \& Downing 1994). This process may be partially explained by an inevitable statistical averaging of fluctuations in abundance or biomass of primary producers as communities increase in complexity (Doak et al. 1998). High variability inherent to some guilds of primary producers may strongly influence patterns of organic matter provision to higher trophic levels. For example, coastal food webs are fuelled by 2 primary sources of organic matter: highly seasonal pelagic phytoplankton that is subject to distinct bloom events (Burrell 1988) and more consistently available benthic macroalgae (e.g. Duggins et al. 1989). Physical influences on the availability and relative composition of these organic matter sources result in complex spatial heterogeneity in food web structure. This is particularly apparent in regions with topographically complex coastlines.

Primary productivity in Fiordland, southwest New Zealand is mediated by gradients in light, wave exposure and nutrient source pools, which produce gradients in the variability, abundance and composition of organic matter sources along the axes of the multiple fjords (Goebel et al. 2005, Wing et al. 2007). Diatom blooms across Fiordland occur intermittently in spring and autumn and are initiated by wind driven mixing of nutrients from stratified water layers (Goebel et al. 2005). Much of this pelagic productivity may be consumed by the abundant mussel beds distributed along the fjord walls (Wing \& Leichter 2011). Conversely, availability of organic matter derived from macroalgae to a diverse community of grazers and detritivores is seasonally more stable but confined to distinct kelp bed habitats. Strong spatial gradients exist along the axes of each fjord from wellilluminated, wave-exposed kelp dominated habitats in 30 to $40 \mathrm{~m}$ depth at the fjord entrances to the shaded, quiescent inner-fjord environments where a thin layer of estuarine algae exist only in the shallow 2 to $5 \mathrm{~m}$ depth littoral zone (Cornelisen et al. 2007, Wing et al. 2007). The resulting habitat gradients, which influence the type, diversity and abundance of food available to consumers, are a key bottom-up driver of metapopulation structure for benthic invertebrates (Wing et al. 2008, Wing 2009) and fishes (Rodgers \& Wing 2008).

Omnivores living along environmental gradients often feed differentially in distinct habitat patches (Polis \& Strong 1996). Thus sub-populations, or individuals within them, may shift or diversify their diet so that conspecifics are not always ecologically equivalent among, or even within, sites or habitats (Bolnick et al. 2003). A corollary is that landscape-scale patterns in individual specialisation can drive spatial patterns in basal organic matter use, resulting in spatial variability in food web stability. We explored these concepts by measuring the between-individual variability in diet of Jasus edwardsii (Fig. 1), a broadspectrum omnivore that is common on New Zealand rocky reefs and exerts strong top-down influences on kelp forest community structure (Langlois et al. 2005, 2006, Shears et al. 2008). The diet of J. edwardsii is taxonomically diverse. Gut content analysis of

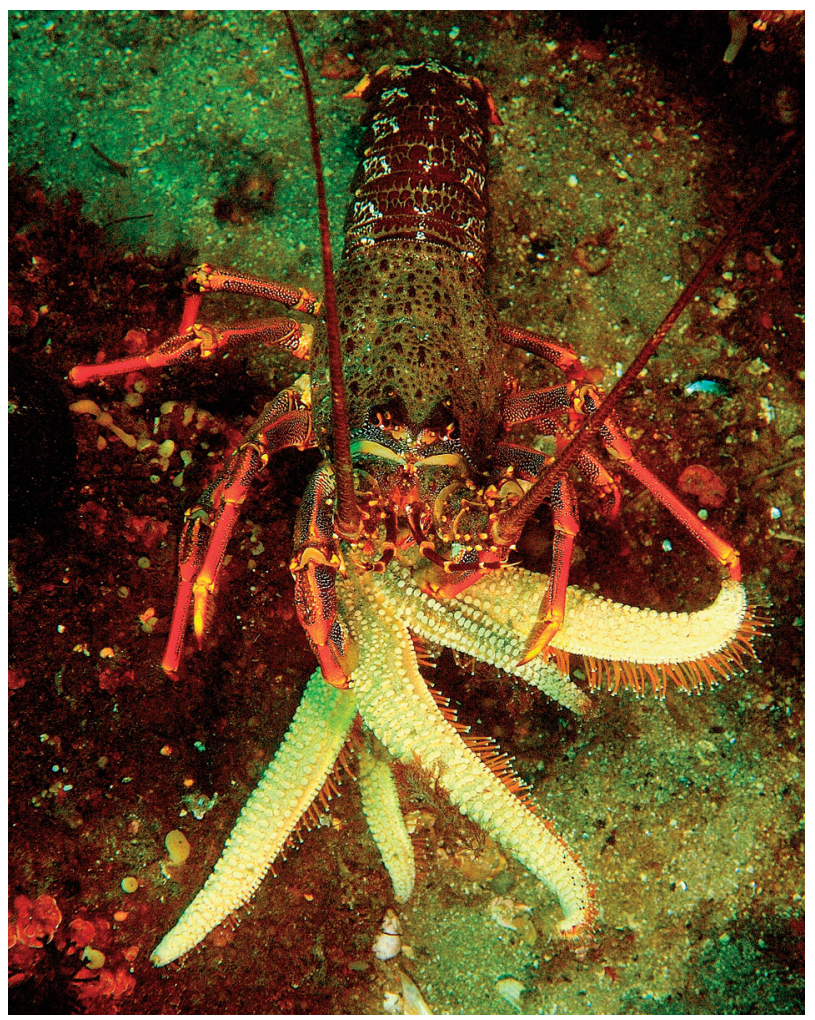

Fig. 1. Jasus edwardsii on Asterostole scabra. Red rock lobster consuming a sea star on a Fiordland rocky reef 
lobsters in northern New Zealand revealed green, brown and red algae, annelida, brachiopoda, bryozoa, crustacea, echinodermata, chordata, foraminifera and mollusca, including examples of saprophagy and cannibalism (S. Kelly unpubl. data). Gut content analysis has the distinct advantage of providing high taxonomic resolution of prey. However, identification of food items can be problematic; differential digestion under-represents soft items, inference is made on ingestion but not assimilation and only a short period of time is represented. In addition, an important issue left unresolved by quantifying prey diversity is how resource use influences the access to and composition of basal organic matter source pools. In this case, stable isotope analysis is a useful complementary approach (Fry 2006).

Natural abundances of stable isotope ratios of carbon $\left({ }^{12} \mathrm{C}:{ }^{13} \mathrm{C}\right)$ and nitrogen $\left({ }^{14} \mathrm{~N}:{ }^{15} \mathrm{~N}\right)$ provide definitive, time integrated tracers of organic matter through food webs (Fry 2006). Variation in the relative amount of isotopes that are fixed during metabolic processes results in characteristic signatures of primary consumers. This variation is conserved as predictable step-wise discrimination that occurs between trophic levels in a food web (DeNiro \& Epstein 1978, 1981, McCutchan et al. 2003, Suring \& Wing 2009). Stable isotopic signatures of carbon $\left(\delta^{13} \mathrm{C}\right)$ change little with trophic level (DeNiro \& Epstein 1978) and can be used to resolve the mix of primary organic matter sources for a consumer. In contrast, the stable isotopic signature of nitrogen $\left(\delta^{15} \mathrm{~N}\right)$ of a consumer is enriched typically 2 to $4 \%$ relative to its diet (DeNiro \& Epstein 1981, McCutchan et al. 2003). Thus $\delta^{15} \mathrm{~N}$ is a continuous integrative measure of trophic position that is especially useful for measuring variable degrees of omnivory, where the high variation in $\delta^{15} \mathrm{~N}$ among individuals of a species is indicative of high variation in food-web complexity or length (Cabana \& Rasmussen 1994). Using stable isotopes to measure individual variation in foraging specialisation and trophic dispersion represents a significant scientific advance.

In the present study we used information from subtidal surveys to identify how the distribution of rock lobsters varies across kelp and mussel bed habitats. These habitats represent key links to benthic and pelagic sources of organic matter. We then used information from stable isotope analysis to determine which factors best predict individual level variability in trophic position and in the composition of basal organic matter sources supporting Jasus edwardsii within these habitats. This analysis provides a novel method to quantify the effects of nutritional gradients on niche breadth in terms of organic matter sources and demonstrates the likely influence of habitat type on individual variability in diet and population structure of a broad-spectrum omnivore.

\section{MATERIALS AND METHODS}

\section{Rock lobster surveys}

Presence or absence of lobsters was recorded at 60 sites in Fiordland between 2003 and 2009 during subtidal surveys at 15, 10 and $5 \mathrm{~m}$ depth (Fig. 2). Two to 4 pairs of research divers collected data during each survey, and searching for lobsters was a specific objective of at least 1 diver pair. An average of 2.7 surveys (maximum $=9$ ) took place at each site over the $7 \mathrm{yr}$ period. If lobsters were observed during any survey they were recorded as present at the site.

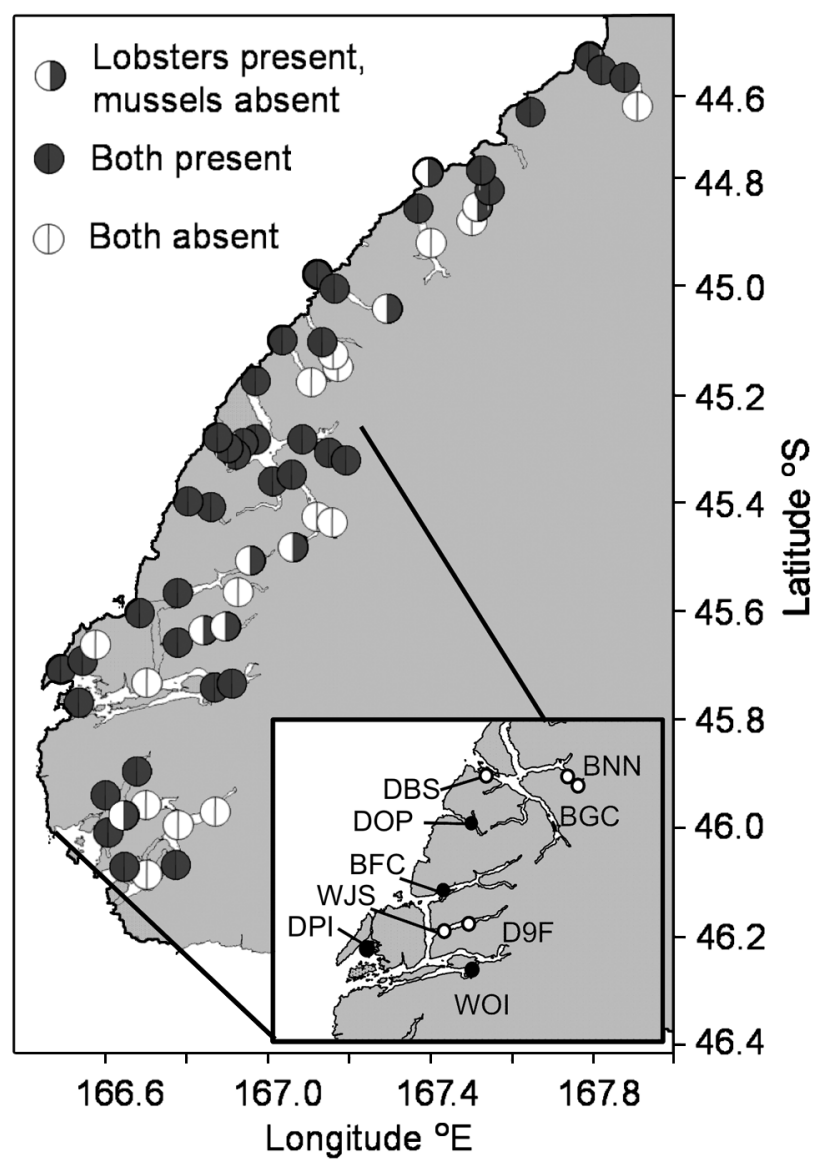

Fig. 2. Jasus edwardsii. Study site locations for rock lobster surveys across Fiordland (southwest New Zealand). Insert: Study sites (O) in Ecklonia radiata kelp forests and (O) where kelp density is $<1$ stipe $\mathrm{m}^{-2}$ used for rock lobster diet analysis. See Table 1 legend for site abbreviations 


\section{Mussel band surveys}

Presence or absence of Mytilus edulis galloprovincialis and the less common mussel species Perna canaliculus and Aulacomya atra maoriana throughout Fiordland was ascertained by surveying the region of rock walls 0 to $5 \mathrm{~m}$ below high tide at the same 60 sites during surveys between 2006 and 2009. If a mussel band was observed, mussels were recorded as present at the site.

\section{Kelp bed surveys}

Density of the dominant stipitate kelp Ecklonia radiata was measured at the 60 Fiordland sites between 2003 and 2009 using paired 2 m $^{2}$ quadrats with effort stratified evenly across depth strata centered at 5, 10 and $15 \mathrm{~m}$. Seven to 28 quadrat-pairs were measured during each survey (mean =17) for a total of 88 surveys, and each site was surveyed in 1 to 4 of the $7 \mathrm{yr}$ (mean $=1.6)$. Overall mean stipe density and standard error were calculated as the hierarchical mean of means and standard errors (SE) by depth, survey and site. Sites where this density exceeded 1 stipe $\mathrm{m}^{-2}$ were defined as 'kelp bed' habitat.

\section{Rock lobster resource use determined by stable isotope analysis}

In February 2008, 80 lobsters were caught by hand at 9 sites throughout central Fiordland, mean $\pm \mathrm{SE}=8.8 \pm 1.56$ ind. site $^{-1}$ (Fig. 2 insert). This suite of sites was sampled to represent a diverse array of environmental conditions in which Jasus edwardsii are found, spanning sites dominated by kelp and mussel beds in the system (Wing et al. 2007). The carapace length (CL) of each lobster was measured to the nearest mm using Vernier callipers. The sex of each individual was determined by visual inspection of the fifth pereopod (terminal walking leg), which in females is sub-chelate, and by the presence of paired ventral glands on males. Lobsters were non-lethally sampled using the autonomic limb severance response to remove 1 penultimate pereopod per individual before release. Leg muscle was dried at $60^{\circ} \mathrm{C}$ and homogenized to a fine powder with a mortar and pestle.
Stable isotope analyses were performed in the Department of Chemistry at University of Otago. Samples were analysed for $\delta^{13} \mathrm{C}$ and $\delta^{15} \mathrm{~N}$ on a Europa Scientific 20-20 update stable isotope mass spectrometer interfaced to a Carlo Erba NA1500 elemental analyser in continuous flow mode (precision: $0.2 \%$ for $\delta^{13} \mathrm{C}, 0.3 \%$ for $\left.\delta^{15} \mathrm{~N}\right)$. Analysis was calibrated to EDTA laboratory standard reference (Elemental Microanalysis) and standardised against international standards (IAEACH-6 for carbon, IAEAN1 and IAEAN2 for nitrogen). Results are expressed in the standard delta notation (e.g. Peterson \& Fry 1987) where, for example, $\delta^{13} \mathrm{C}=\left[\left(\mathrm{R}_{\mathrm{smpl}} / \mathrm{R}_{\mathrm{std}}\right)-1\right] \times 1000$, where $\mathrm{R}_{\text {smpl }}={ }^{13} \mathrm{C} /{ }^{12} \mathrm{C}$ of sample and $\mathrm{R}_{\text {std }}={ }^{13} \mathrm{C} /{ }^{12} \mathrm{C}$ of Peedee belemnite limestone. The primary standard for $\delta^{15} \mathrm{~N}$ was atmospheric nitrogen.

\section{Isotopic mixing models and trophic level}

Spatial variation in $\delta^{15} \mathrm{~N}$ and $\delta^{13} \mathrm{C}$ of phytoplankton samples is generally low in this system (Wing et al. 2008), thus the stable isotopic signature of phytoplankton was characterised by sampling suspended particulate organic matter (SPOM) during a phytoplankton bloom (Wing et al. 2008) (Table 1). In contrast, the ecophysiology of the dominant stipitate kelp Ecklonia radiata varies along the fjord axis rela-

Table 1. Jasus edwardsii. (a) Sample size (n), isotopic values $\left(\delta^{15} \mathrm{~N}, \delta^{13} \mathrm{C}\right)$ and carapace lengths (CL) for red rock lobsters captured at each of 9 sites throughout Fiordland and (b) same parameters for lobsters, macroalgal and suspended particulate organic matter (SPOM) source pools across all sites. All measured values are means \pm 1 SE. BFC: Breaksea First Cove, BGC: Bradshaw Green's Cave, BNN: Bradshaw Nicole's Nook, D9F: Dusky Nine Fathom Pass, DBS: Doubtful Bauza South, DOP: Dagg Otago Point, DPI: Dusky Parrot Island, WJS: Wetjacket South Wall, WJO: Wetjacket Oke Island, na: not applicable

\begin{tabular}{|c|c|c|c|c|c|}
\hline & $\mathrm{n}$ & $\delta^{13} \mathrm{C}$ & $\delta^{15} \mathrm{~N}$ & $\mathrm{C}: \mathrm{N}$ ratio & CL (mm) \\
\hline \multicolumn{6}{|c|}{ (a) Lobsters by site } \\
\hline $\mathrm{BFC}^{\mathrm{a}}$ & 4 & $-17.1 \pm 0.4$ & $13.5 \pm 0.4$ & $3.2 \pm 0.07$ & $105.4 \pm 6.3$ \\
\hline BGC & 17 & $-18.2 \pm 0.3$ & $12.0 \pm 0.3$ & $2.9 \pm 0.02$ & $101.0 \pm 3.4$ \\
\hline $\mathrm{BNN}$ & 9 & $-17.4 \pm 0.3$ & $12.4 \pm 0.4$ & $3.1 \pm 0.04$ & $113.0 \pm 4.2$ \\
\hline D9F & 6 & $-16.3 \pm 0.5$ & $13.1 \pm 0.1$ & $3.0 \pm 0.07$ & $113.2 \pm 7.2$ \\
\hline DBS & 16 & $-17.0 \pm 0.8$ & $12.7 \pm 0.1$ & $3.1 \pm 0.02$ & $109.3 \pm 3.6$ \\
\hline $\mathrm{DOP}^{\mathrm{a}}$ & 4 & $-17.2 \pm 0.2$ & $12.9 \pm 0.3$ & $3.1 \pm 0.06$ & $140.6 \pm 14.6$ \\
\hline $\mathrm{DPI}^{\mathrm{a}}$ & 13 & $-17.2 \pm 0.1$ & $13.6 \pm 0.2$ & $3.0 \pm 0.04$ & $118.3 \pm 5.1$ \\
\hline WJS & 5 & $-16.2 \pm 0.2$ & $13.8 \pm 0.1$ & $3.0 \pm 0.05$ & $129.1 \pm 7.9$ \\
\hline $\mathrm{WJO}^{\mathrm{a}}$ & 8 & $-16.7 \pm 0.1$ & $13.3 \pm 0.1$ & $3.0 \pm 0.02$ & $113.4 \pm 6.0$ \\
\hline \multicolumn{6}{|l|}{ (b) All sites } \\
\hline Lobsters & 82 & $-17.2 \pm 0.1$ & $12.9 \pm 0.1$ & $3.0 \pm 0.04$ & $112.8 \pm 2.0$ \\
\hline Macroalgae & 42 & $-18.0 \pm 0.2$ & $4.2 \pm 0.4$ & $19.6 \pm 0.3$ & na \\
\hline SPOM & 100 & $-21.3 \pm 0.1$ & $6.6 \pm 0.2$ & $11.2 \pm 0.4$ & na \\
\hline
\end{tabular}


tive to topographic shading and wave exposure (Wing et al. 2007) and spatial patterns in $\delta^{15} \mathrm{~N}$ and $\delta^{13} \mathrm{C}$ in the dominant estuarine algae Ulva pertusa vary with nutrient source pools and along physical gradients (Cornelisen et al. 2007). Because of this, a weighted aggregate isotopic signature for macroalgae was used that incorporated variation in species composition and isotopic signatures along the fjord axis (after Wing et al. 2008) (Table 1).

A 2-step iterative procedure was used to determine the basal organic matter used and trophic level of individual lobsters. (1) An individual-based 2-source mass balance model after Phillips \& Gregg (2001) calculated the relative contribution of macroalgae and SPOM to the diet of each rock lobster using $\delta^{13} \mathrm{C}$. In this step an approximation of trophic level was used to estimate trophic discrimination of $\delta^{13} \mathrm{C}$. The results of this model were used to estimate the corresponding $\delta^{15} \mathrm{~N}$ of the mixture of organic matter sources supporting each individual $\left(\delta^{15} \mathrm{~N}_{\text {base }}\right)$. Trophic level was then calculated for each lobster from $\delta^{15} \mathrm{~N}_{\text {base }}$ defined as: $\left[\left(\delta^{15} \mathrm{~N}_{\text {consumer }}-\delta^{15} \mathrm{~N}_{\text {base }}\right) / \Delta_{n}\right]+1$, where $\Delta_{n}$ is the enrichment per trophic level so that level 1 was $1^{\bullet}$ productivity after Post (2002). (2) The resulting estimate of trophic level was then iterated back into the mass balance model until a stable solution was obtained for both the mixture of organic matter sources and trophic level.

Trophic discrimination factors (TDFs) are important sources of error in food web modelling (Vanderklift \& Ponsard 2003). To improve the accuracy of our models, we used the average TDFs for aquatic environments of $+0.4 \%$ o ( $\mathrm{SE} \pm 0.17$ ) for $\delta^{13} \mathrm{C}$ and $+2.3 \%$ ( $\mathrm{SE} \pm 0.28$ ) for $\delta^{15} \mathrm{~N}$, after McCutchan et al. (2003), for each enrichment step except the last, where we used species- and tissue-specific values of $+0.8 \%$ ( $\mathrm{SE} \pm$ 0.10 ) for $\delta^{13} \mathrm{C}$ and $+3.3 \%$ ( $\mathrm{SE} \pm 0.15$ ) for $\delta^{15} \mathrm{~N}$ for Jasus edwardsii muscle tissue (Suring \& Wing 2009).

We then modeled the sensitivity of our estimates to literature values of variability in TDFs (sensu McLeod \& Wing 2007). The $2 \mathrm{TDF}$ s were altered by $\pm 1 \mathrm{SE}$ and individual estimates for composition of organic matter sources and trophic level were recalculated to provide a measure of sensitivity to reported error for our foodweb model. This was reported as error around our individual estimates of trophic level and composition of basal organic matter sources.

\section{Rock lobster relative abundance surveys}

In February 2007 and 2008, lobster abundance was estimated at the same 9 sites throughout Fiordland
(Fig. 2 insert). During stratified subtidal surveys of marine biota at 5, 10 and $15 \mathrm{~m}$ depth, 4 pairs of divers recorded cumulative counts of lobsters that were adjusted for dive time. A stratified mean and SE was calculated among years and diver pairs.

\section{Kelp relative abundance surveys}

In February 2008, density of the dominant canopy forming kelp Ecklonia radiata was estimated as described above using six $2 \mathrm{~m}^{2}$ quadrat pairs per depth strata at the 9 Fiordland sites. A stratified mean and SE was calculated for each site.

\section{Mussel density surveys}

We characterised the relative abundance of mussels at the 9 Fiordland sites using a photoquadrat survey in February 2008. Percent cover of Mytilus edulis galloprovincialis, Perna canaliculus and Aulacomya atra maoriana was calculated as an index of their combined abundance. At each site, 25 photoquadrats using a $0.17 \mathrm{~m}^{2}$ framer and a Nikon D200 with a $12 \mathrm{~mm}$ lens were randomly distributed in the mussel band (0 to $5 \mathrm{~m}$ depth). Percent cover of mussels was calculated for each image using Image $\mathrm{J}$ software (NIH) and used to calculate site averages. Stratified means and SE were calculated for each site.

\section{Statistical methods}

We used distance based linear models (DISTLM) incorporating corrected Akaike's information criterion $\left(\mathrm{AIC}_{\mathrm{C}}\right)$ model selection criteria after Legendre \& Anderson (1999) and McArdle \& Anderson (2001) in PERMANOVA+ for PRIMER-e version 6 statistical software (Anderson et al. 2008). This method was equivalent to univariate regression but with more robust statistical inferences by virtue of a permutational approach. Analyses were conducted on raw data because initial transformations did not improve the fit. Similarity matrices were based on Euclidean distances among sites (Model Set 1) and individual lobsters (Model Sets 2 to 5) and models were fitted using $9 \times$ $10^{5}$ unrestricted permutations of the raw data. Using data from 60 sites, we compared the relative explanatory power of the occurrence of a mussel band and kelp beds for the occurrence of rock lobsters. Because 21 of these sites were in no-take marine reserves 
(17 that were established in 2005, 4 in 1993) and Jasus edwardsii populations in New Zealand respond positively to marine reserves (Kelly et al. 2000, Pande et al. 2008), we also included management unit (reserve or non-reserve) as a factor in this model set. Using data collected at 9 sites, we compared the relative importance of population structure metrics (sex, carapace length \& relative abundance) and habitat descriptors (kelp density and mussel \% cover) in explaining the variance in trophic level and in carbon source use of individual lobsters. We did not combine population structure and habitat descriptor models out of caution because data for the former were collected in a single survey whilst data for the latter were collected over a series of surveys, so that the scale of variability might differ with the different aggregates of data.

\section{RESULTS}

\section{Rock lobster occurrence}

The model containing both predictor variables (mussels and kelp) explained the most variation in the presence/absence of lobsters at 60 sites across Fiordland (Table 2). Lobsters were found at all sites where both a mussel band and a kelp bed were present, 10 out of 12 sites containing only kelp beds, all of the 37 sites containing mussel bands and at 8 sites without a mussel band (Fig. 2). The occurrence of a mussel band incurred the greatest factor weighting and statistically accounted for $>50 \%$ of the variation in the data. Whether sites were in a marine reserve or not held very little statistical weighting (Table $2, \mathrm{r}^{2}=$ $0)$, so this factor was not investigated further.

\section{Rock lobster diet: trophic level}

Variance in individual trophic level was best explained by the population structure model containing the variables Sex and Rock Lobster Abundance (Table 3). The effect of removing Sex from the model was small and Rock Lobster Abundance bore the greatest factor weight. Lobsters fed at lower trophic levels at sites where they were more abundant (Fig. 3a). There was little relationship detected between lobster size (CL) and trophic level $\left(\mathrm{r}^{2}=0.01\right)$, and the size of lobsters bore the lowest factor weight (Table 3).

Using habitat descriptors, variance in trophic level was best explained by Mussel Density (Table 4). Lobsters fed at lower trophic levels where mussels were abundant (Fig. 3b) and kelp was scarce (Fig. 3c) but the explanatory power of this model was low $\left(\mathrm{r}^{2}<0.2\right)$, and the relationship was likely non-linear.

\section{Rock lobster diet: Source pool utilization}

Using the model set that described population structure, 'Rock Lobster Abundance' was the predictor that best explained variation in composition of basal organic matter sources used by lobsters (i.e. the fraction of their diet derived from SPOM versus macroalgae). Lobsters received a greater fraction of their diet from pelagically-derived organic matter at sites where they were more abundant (Table 5, Fig. 3d). There was little relationship detected between 

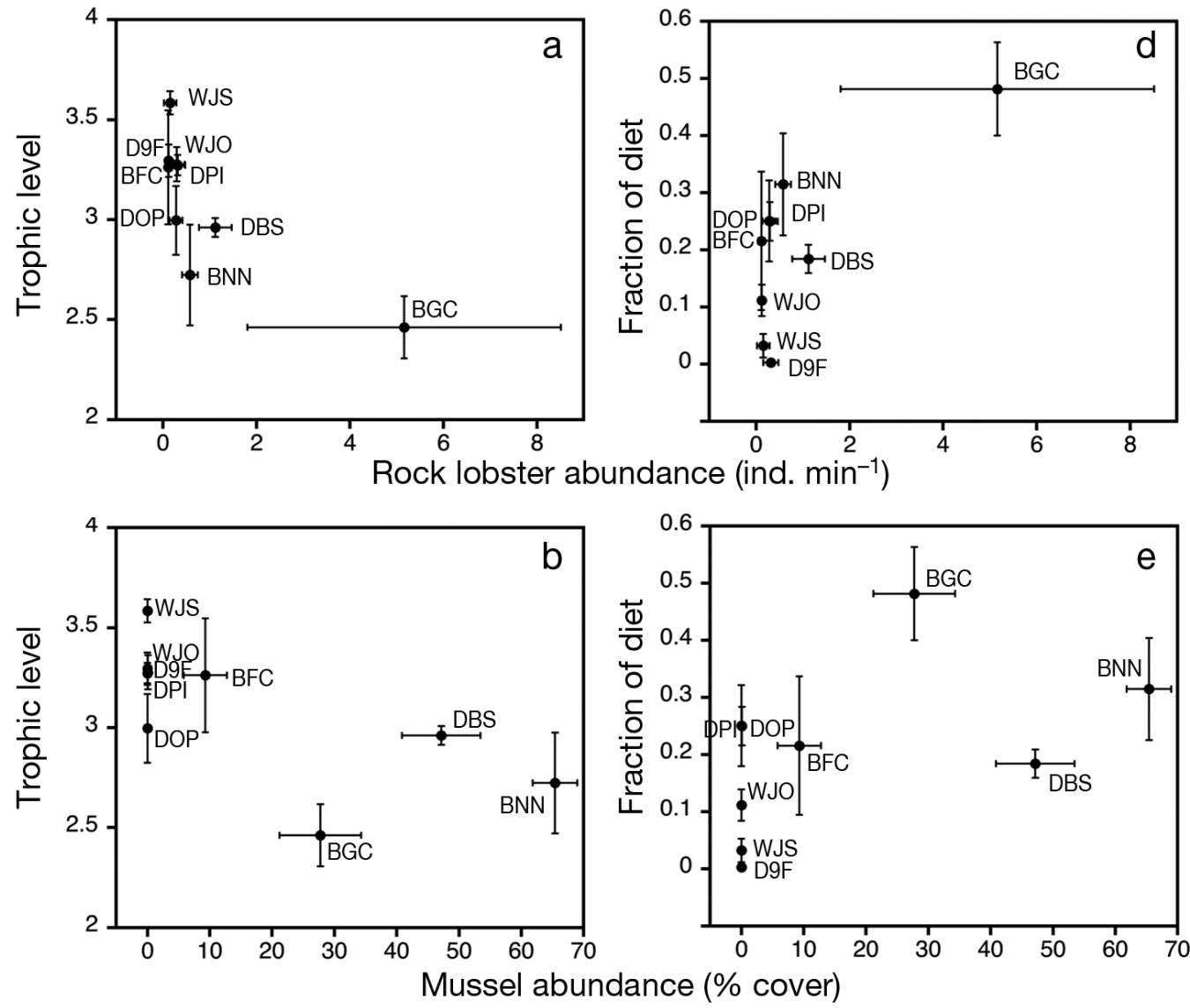

Fig. 3. Jasus edwardsii, Mytilus edulis galloprovincialis and Ecklonia radiata. $(\mathrm{a}, \mathrm{b}, \mathrm{c})$ Weighted trophic level and $(\mathrm{d}, \mathrm{e}, \mathrm{f})$ proportion of diet derived from suspended particulate organic matter (SPOM) versus relative abundances of $(\mathrm{a}, \mathrm{d})$ rock lobsters, $(b, e)$ mussels, and (c,f) kelp, including (dashed line) kelp density (stipes $\mathrm{m}^{-2}$ ) for each of 9 collection sites. Means \pm SE. See Table 1 legend for site abbreviations
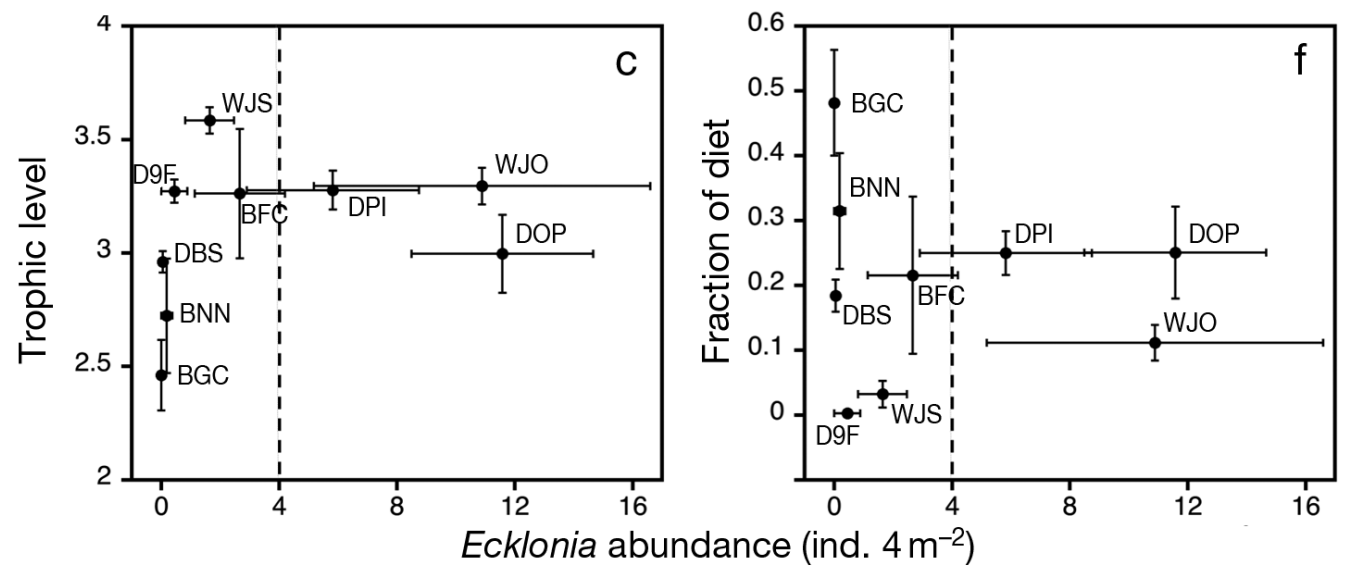

Table 4. Jasus edwardsii. Relative explanatory power of habitat indicators grouped as Model Set 3 for rock lobster trophic level at 9 sites in Fiordland using corrected Akaike's information criterion $\left(\mathrm{AIC}_{\mathrm{c}}\right)$. K: no. of model parameters; RSS: residual sum of squares; $\Delta_{i}$ : difference in model AIC from minimum $\mathrm{AIC} ; w_{i}$ : model AIC weight

\begin{tabular}{|lccccccc|}
\hline Model & $K$ & $\mathrm{RSS}$ & $\mathrm{r}^{2}$ & $\mathrm{AIC}_{\mathrm{c}}$ & $\Delta_{i}$ & $w_{i}$ & $\begin{array}{c}\text { Factor } \\
\text { weight }\end{array}$ \\
\hline Mussel density & 1 & 18.70 & 0.17 & -109.67 & 0.00 & 0.67 & 0.96 \\
Mussels + Kelp & 2 & 18.58 & 0.17 & -108.03 & 1.64 & 0.29 & \\
Kelp density & 1 & 20.09 & 0.10 & -104.00 & 5.67 & 0.04 & 0.33 \\
\hline
\end{tabular}

lobster size (CL) or sex and source-pool use $\left(r^{2}=0.04\right.$ and 0.03 respectively) and sex of lobsters bore the lowest factor weight (Table 3).

Comparing habitat descriptors, variation in organic matter source pools to lobsters was best explained by 'Mussel Density' (Table 6). However, $\mathrm{r}^{2}$ values for all the models in this set were very low $(<0.1)$ and key relationships were likely non-linear (Fig. 3e,f). 
Table 5. Jasus edwardsii. Relative explanatory power of population structure metrics grouped as Model Set 4 for use of basal organic matter sources by rock lobsters at 9 sites in Fiordland using corrected Akaike's information criterion $\left(\mathrm{AIC}_{\mathrm{c}}\right)$. CL: carapace length. $K$ : no. of model parameters; RSS: residual sum of squares; $\Delta_{i}$ : difference in model AIC from minimum AIC; $w_{i}$ : model AIC weight

\begin{tabular}{|c|c|c|c|c|c|c|c|}
\hline Model & $K$ & RSS & $\mathrm{r}^{2}$ & $\mathrm{AIC}_{\mathrm{c}}$ & $\Delta_{i}$ & $w_{i}$ & $\begin{array}{l}\text { Factor } \\
\text { weight }\end{array}$ \\
\hline Abundance & 1 & 3.20 & 0.27 & -249.12 & 0.00 & 0.55 & 0.99 \\
\hline CL + Abundance & 2 & 3.20 & 0.27 & -247.06 & 2.06 & 0.20 & \\
\hline Sex + Abundance & 2 & 3.20 & 0.27 & -246.97 & 2.15 & 0.19 & \\
\hline All & 3 & 3.19 & 0.27 & -245.02 & 4.10 & 0.07 & \\
\hline CL & 1 & 4.17 & 0.04 & -228.18 & 20.94 & 0.00 & 0.27 \\
\hline Sex & 1 & 4.22 & 0.03 & -227.23 & 21.89 & 0.00 & 0.26 \\
\hline $\mathrm{CL}+\mathrm{Sex}$ & 2 & 4.16 & 0.05 & -226.21 & 22.91 & 0.00 & \\
\hline
\end{tabular}

Table 6. Jasus edwardsii. Relative explanatory power of habitat indicators grouped as Model Set 5 for use of basal organic matter sources by rock lobsters at 9 sites in Fiordland using corrected Akaike's information criterion $\left(\mathrm{AIC}_{\mathrm{c}}\right) . K$ : no. of model parameters; RSS: residual sum of squares; $\Delta_{i}$ : difference in model AIC from minimum $\mathrm{AIC} ; w_{i}$ : model AIC weight

\begin{tabular}{|lccccccc|}
\hline Model & $K$ & $\mathrm{RSS}$ & $\mathrm{r}^{2}$ & $\mathrm{AIC}_{\mathrm{c}}$ & $\Delta_{i}$ & $w_{i}$ & $\begin{array}{c}\text { Factor } \\
\text { weight }\end{array}$ \\
\hline Mussel density & 4 & 4.14 & 0.05 & -228.88 & 0.00 & 0.57 & 0.78 \\
Kelp density & 4 & 4.23 & 0.03 & -227.01 & 1.87 & 0.22 & 0.43 \\
Mussels + Kelp & 4 & 4.13 & 0.05 & -226.80 & 2.08 & 0.20 & \\
\hline
\end{tabular}

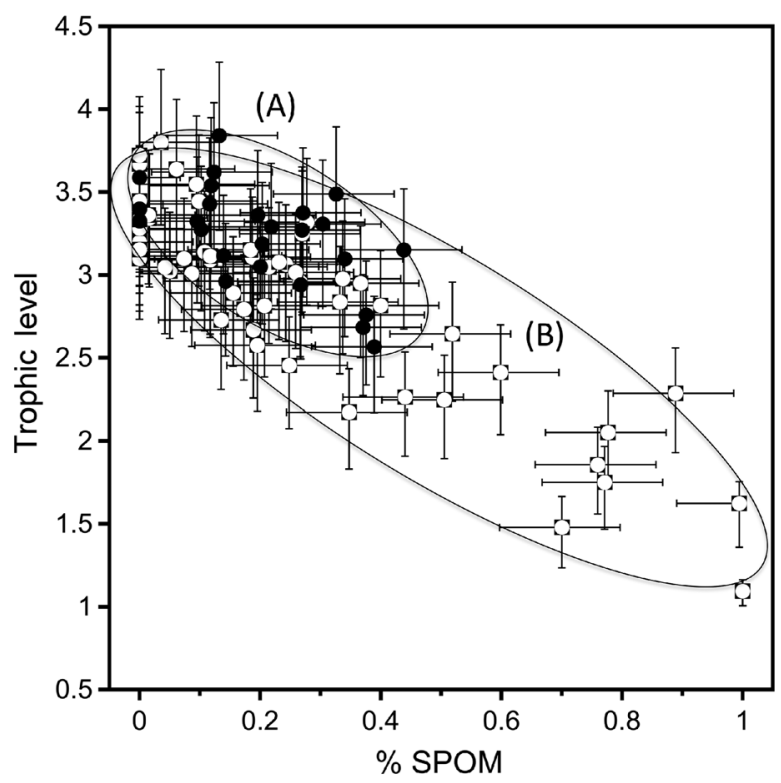

Fig. 4. Jasus edwardsii. Mean weighted trophic level of individual lobsters versus proportion of diet derived from suspended particulate organic matter (SPOM) for each site at (๑) sites in kelp forests versus (O) sites where kelp density is $<1$ stipe $\mathrm{m}^{-2}$. Error bars indicate variability attributed to \pm 1 $\mathrm{SE}$ in trophic discrimination factors for $\delta^{13} \mathrm{C}$ and $\delta^{15} \mathrm{~N}$ overlaid with the results of the (A) permutational multivariate analysis of variance (PERMANOVA) and (B) permutational tests of multivariate dispersion (PERMDISP) analyses

\section{Dietary dispersion inside versus outside kelp beds}

At sites with low kelp density $(<1$ stipe $\mathrm{m}^{-2}$ ), lobster populations fed at a greater range of trophic levels ( 2.25 to 3.5) and the range of basal organic matter source pool use was more diverse (0 to $58 \%$ SPOM) than at sites containing kelp beds (trophic level $\sim 2.9$ to $3.25,8$ to $32 \%$ SPOM) (Fig. 3c,f). To further explore this pattern we tested for statistical differences in individual diversification of basal organic matter use and trophic levels inside and outside of kelp beds. Individual estimates of trophic level and $\%$ of diet derived from SPOM were used to construct a resemblance matrix based on Euclidean distances of the raw data. We used a 1-way PERMANOVA (permutational multivariate analysis of variance) for the factor Habitat (2 levels, fixed) with $9 \times 10^{5}$ unrestricted permutations of the raw data to conduct an exact test, which resolved dietary differences between the 2 habitats $\left(F_{1,78}=7.92, \mathrm{p}=0.05\right)$. We used a permutational distance based test for homogeneity of multivariate dispersions (PERMDISP) based on distances to centroids (Anderson et al. 2008) to test for differences in dietary dispersion between the 2 habitats. At sites of low kelp density, there was greater variability in trophic level and organic matter source to individual lobsters than those in kelp beds, where lobsters more consistently fed at a high trophic level and more consistently used organic matter from macroalgae $\left(F_{1,78}=9.98, \mathrm{p}=\right.$ 0.01 , Fig. 3). Our modelling of the sensitivity of the food web model output to error in trophic discrimination factors of both $\delta^{15} \mathrm{~N}$ and $\delta^{13} \mathrm{C}$ revealed that this pattern was robust (Fig. 4, error bars).

\section{DISCUSSION}

We provide evidence for spatial variation in resource use by a broad-spectrum omnivore where individual variability in use of organic matter sources and trophic position is linked with kelp bed habitat at a regional scale. Results from a broad scale regional survey indicated that among the habitat indicators considered the presence of a mussel band was the best statistical predictor of the presence of Jasus edwardsii in Fiordland. Lobsters were found to occur 
inside and outside of kelp bed habitat across the region. This pattern is consistent with known dietary preferences of lobsters in Fiordland, which consists of mussels (Witman \& Grange 1998). Further, lobsters are less abundant and their populations have less mature size structures in areas where anthropogenic habitat degradation has lead to declines of heterotrophic bivalves (Jack et al. 2009, Jack \& Wing 2010). These patterns provided a baseline from which to test differences in trophic position and use of organic matter sources among habitats with and without kelp.

At a core suite of sites we find evidence for (1) less variable composition of organic matter sources and (2) less variation in trophic level for lobsters sampled within kelp bed habitats relative to those sampled outside of kelp beds. Kelp beds are characterized by complex food webs, often with strong and complex trophic linkages (Estes et al. 2004). Within these food webs, relatively seasonally consistent provision of organic matter from macroalgae may come from direct grazing, suspension feeding or recycling by detritivores. Jasus edwardsii feed on each of these prey guilds within kelp beds, resulting in a consistent mixture of organic matter sources from a diverse community of prey. The result is a broad-scale averaging of trophic level and composition of organic matter sources, or 'portfolio effect'. This mechanism likely results in the low individual variability in resource use that we observed in lobsters from kelp bed habitats.

Outside of kelp bed habitats lobsters fed at a wider range of trophic levels and at an overall lower mean trophic level. In these habitats we also observed increased variability in the mixture of organic matter sources supporting food webs preyed upon by rock lobsters. Thus, individual variability in feeding likely resulted in a broad trophic diversification in terms of provision of organic matter from basal carbon sources. A larger portion of the population was reliant on prey linked to organic matter from phytoplankton, an inherently more seasonally variable organic matter source, and feeding occurred generally within less complex food webs.

This observed spatial heterogeneity in food web structure has potential implications for local demographic dynamics and resulting population structure at the landscape scale. Shorter food webs with simple linkages are less stable than complex webs, where high connectivity through multiple interactions confers stability (McCann \& Hastings 1997). At sites where they were highly aggregated, lobsters fed at a lower average trophic level and utilised a greater proportion of pelagically derived organic matter in their diets. These results suggest an overall greater exploitation of the filter-feeding guild as a prey base. At Bradshaw Green's Cave (BGC) where mussels were observed in a dense band, this food source supported a highly aggregated lobster population with over twice the density of rock lobsters than that observed at the other sites. While we detect a declining trend of trophic level with lobster abundance within the other study sites the overall relationship is dominated by the highly aggregated population at BGC. We predict that the population of lobsters at $\mathrm{BGC}$ receives a less stable provision of organic matter than lobster populations feeding within kelp bed food webs.

These observations indicate that lobsters in this system are likely employing a range of ecological strategies. The extremes of these are: (1) in kelp bed habitats, core populations of lobsters at intermediate density feed on a diverse range of prey fuelled from autochthonous sources; and (2) outside kelp beds, discrete patches of prey, fuelled from a range of allochthonous and autochthonous sources, exist until a site is colonised, when satellite populations of lobsters may become highly locally aggregated and opportunistically exploit (potentially eventually overexploit) these highly aggregated resources.

Stable isotopes are tropic integrators, representing the diet of an animal over a time-scale relative to the isotopic half-life of the tissue measured (Fry 2006). In Jasus edwardsii muscle, this half-life is $147 \mathrm{~d}$ (Suring $\&$ Wing 2009). Thus the isotopic variability measured here is representative of enduring differences in diet between sample populations on the order of 1 to $2 \mathrm{yr}$. These patterns are consistent with known movements of red rock lobsters, which classify residency patterns into 2 distinct modes and imply alternate food web interactions. Sub-adult J. edwardsii may travel over large distances and form 'runs' or largescale migrations of individuals (Annala \& Bycroft 1993). Thus a proportion of the population is highly mobile and prone to strong aggregation behaviour. This strategy is consistent with exploitation of an ephemeral, highly aggregated resource where dense patches of animals display high variability in trophic position and source pool exploitation as they move among distinct aggregated food patches (Figs. 3b \& 4). Alternatively, mature animals are often territorial and inhabit individual rocky reef patches for up to 13 yr (MacDiarmid 1991). This strategy is consistent with a long-term residency where individuals consistently feed broadly across more complex food webs, representing a more even mixture of basal carbon sources and higher trophic level (Figs. 3c \& 4). We do 
not have information on residency or migration patterns for the individuals sampled in the present study. Nevertheless the patterns we observe in variability in $\delta^{13} \mathrm{C}$ and $\delta^{15} \mathrm{~N}$ among habitats are consistent with observed behaviours.

While our results are consistent with a strong influence of kelp forest habitats on variability in resource use by rock lobsters, several important caveats must accompany this interpretation. Our results are restricted to correlative observations between demographic structure of subpopulations, habitat variability and proxies for trophic position across a complex environment. Accordingly we must restrict our conclusions to observation of covariability rather than causation of these factors on resource use. Further, the ability to resolve use of organic matter sources in complex food webs relies on an understanding of variability in trophic discrimination factors associated with fractionation of $\delta^{13} \mathrm{C}$ and $\delta^{15} \mathrm{~N}$ at each trophic level. While resolution of trophic discrimination factors is rarely available for each node in a complex food web (Newsome et al. 2010), information on natural variability among systems can be gleaned from meta-analyses and from dietary manipulation experiments on individual consumers. In the present example we used reported variance in tropic discrimination factors of $\delta^{13} \mathrm{C}$ and $\delta^{15} \mathrm{~N}$ in aquatic environments (McCutchan et al. 2003) and from Jasus edwardsii (Suring \& Wing 2009) to test sensitivity of our results and found that the observed patterns are robust when applied across food webs. However, our analysis did not take into account bias that might be imposed by systematic differences in trophic discrimination among groups (Newsome et al. 2010) and would benefit from higher resolution of trophic discrimination factors in the system.

In the present marine example, individual variability in resource use supporting lobster subpopulations is strongly linked to habitat quality as defined by resource availability. These general conditions have been observed in terrestrial systems, where variation in diet at the population level (the between-individual component, BIC) varies along habitat gradients, which corresponds to local diversity and quality of food (e.g. DeGabriel et al. 2009, McArt et al. 2009). In the present study system, the heterogeneous nutritional landscape has important consequences for understanding dynamics of organic matter flux in food webs and bottom-up influences on metapopulation structure (Huxel et al. 2004). The existence of local subpopulations persisting in relatively short food webs based on a more ephemeral organic matter source may enhance temporal and spatial vari- ability in aggregations of high trophic level consumers, where individual variability in trophic position is consistent with reliance on a more limited or ephemeral resource base (Bolnick et al. 2003). Conversely, core habitat areas, where access to organic matter sources is more consistent and where food webs have more linkages, offer a more stable nutritional environment where longer-term subpopulation persistence is more likely maintained.

Food web data such as those presented here support a growing body of evidence that variability in niche breadth is linked to trophic diversity among individuals in a population, which is in this case linked to habitat structure. We encourage incorporation of information on individual variation in trophic position into ecological models to provide a more complete description of the trophic dynamics of marine populations. This will further the development of management strategies that conserve functional food webs and sub-populations that are more likely to act as persistent sources to the regional pool.

Acknowledgements. We thank N. Beer, J. Davis, B. Dickson, P. Hesseltine and D. Clarke for assistance with field and lab work. Monetary support was provided by the Royal Society of New Zealand's Marsden Fund (UO-00213 to S.R.W.) and by the Commonwealth Scholarship \& Fellowship Plan (L.J.).

\section{LITERATURE CITED}

Anderson M, Gorley R, Clarke K (2008) PERMANOVA+ for PRIMER: guide to software and statistical methods. University of Auckland, Auckland

Annala JN, Bycroft BL (1993) Movements of rock lobsters (Jasus edwardsii) tagged in Fiordland, New Zealand. N Z J Mar Freshw Res 27:183-190

Arnould JPY, Cherel Y, Gibbens J, White JG, Littnan CL (2011) Stable isotopes reveal inter-annual and inter-individual variation in the diet of female Australian fur seals. Mar Ecol Prog Ser 422:291-302

Bolnick DI, Svanbäck R, Fordyce JA, Yang LH, Davis JM, Hulsey CD, Forister ML (2003) The ecology of individuals: incidence and implications of individual specialization. Am Nat 161:1-28

Burrell DC (1988) Carbon flow in fjords. Oceanogr Mar Biol Annu Rev 26:143-226

Cabana G, Rasmussen JB (1994) Modelling food chain structure and contaminant bioaccumulation using stable nitrogen isotopes. Nature 372:255-257

Cornelisen CD, Wing SR, Clark KL, Bowman MH, Frew RD, Hurd CL (2007) Patterns in $d^{13} C$ and $d^{15} \mathrm{~N}$ signatures of Ulva pertusa: interaction between physical gradients and nutrient source pools. Limnol Oceanogr 52:820-832

> DeGabriel JL, Moore BD, Foley WJ, Johnson CN (2009) The effects of plant defensive chemistry on nutrient availability predict reproductive success in a mammal. Ecology 90:711-719

DeNiro MJ, Epstein S (1978) Influence of diet on the distrib- 
ution of carbon isotopes in animals. Geochim Cosmochim Acta 42:495-506

- DeNiro MJ, Epstein S (1981) Influence of diet on the distribution of nitrogen isotopes in animals. Geochim Cosmochim Acta 45:341-351

Doak DF, Bigger D, Harding EK, Marvier MA, O'Malley RE, Thomson D (1998) The statistical inevitability of stabilitydiversity relationships in community ecology. Am Nat 151:264-276

$>$ Duggins DO, Simenstad CA, Estes JA (1989) Magnification of secondary production by kelp detritus in coastal marine ecosystems. Science 245:170-173

Estes JA, Danner EM, Doak DF, Konar B and others (2004) Complex trophic interactions in kelp forest ecosystems. Bull Mar Sci 74:621-638

Fry B (2006) Stable isotope ecology. Springer, New York, NY

> Fry B, Mumford PL, Tam F, Fox DD, Warren GL, Havens KE, Steinman AL (1999) Trophic position and individual feeding histories of fish from Lake Okeechobee, Florida. Can J Fish Aquat Sci 56:590-600

Goebel NL, Wing SR, Boyd PW (2005) A mechanism for onset of diatom blooms in a fjord with persistent salinity stratification. Estuar Coast Shelf Sci 64:546-560

Huxel GR, Polis GA, Holt RD (2004) At the frontier of the integration of food web ecology and landscape ecology. In: Polis GA, Power ME, Huxel GR (eds) Food webs at the landscape level. University of Chicago Press, Chicago, IL, p 434-451

> Jack L, Wing SR (2010) Maintenance of old-growth size structure and fecundity of the red rock lobster Jasus edwardsii among marine protected areas in Fiordland, New Zealand. Mar Ecol Prog Ser 404:161-172

> Jack L, Wing SR, McLeod RJ (2009) Prey base shifts in red rock lobster Jasus edwardsii in response to habitat conversion in Fiordland marine reserves: implications for effective spatial management. Mar Ecol Prog Ser 381: 213-222

> Kelly S, Scott D, MacDiarmid AB, Babcock RC (2000) Spiny lobster, Jasus edwardsii, recovery in New Zealand marine reserves. Biol Conserv 92:359-369

> Langlois TJ, Anderson MJ, Babcock RC (2005) Reefassociated predators influence adjacent soft-sediment communities. Ecology 86:1508-1519

Langlois TJ, Anderson MJ, Babcock RC (2006) Inconsistent effects of reefs on different size classes of macrofauna in adjacent sand habitats. J Exp Mar Biol Ecol 334:269-282

Legendre P, Anderson MJ (1999) Distance-based redundancy analysis: testing multispecies responses in multifactorial ecological experiments. Ecol Monogr 69:1-24

MacDiarmid AB (1991) Seasonal changes in depth distribution, sex ratio and size frequency of spiny lobster Jasus edwardsii on a coastal reef in northern New Zealand. Mar Ecol Prog Ser 70:129-141

McArdle BH, Anderson MJ (2001) Fitting multivariate models to community data: a comment on distance-based redundancy analysis. Ecology 82:290-297

McArt SH, Spalinger DE, Collins WB, Schoen ER, Stevenson T, Bucho M (2009) Summer dietary nitrogen availability as a potential bottom-up constraint on moose in southcentral Alaska. Ecology 90:1400-1411

> McCann K, Hastings A (1997) Re-evaluating the omnivorystability relationship in food webs. Proc R Soc London B Biol Sci 264:1249-1254

McCutchan JH, Lewis WM, Kendall C, McGrath CC (2003) Variation in trophic shift for stable isotope ratios of car- bon, nitrogen and sulfur. Oikos 102:378-390

McLeod RJ, Wing SR (2007) Hagfish in the New Zealand fjords are supported by chemoautotrophy of forest carbon. Ecology 88:809-816

> Newsome SD, Tinker MT, Monson DH, Oftedal OT and others (2009) Using stable isotopes to investigate individual diet specialization in California sea otters (Enhydra lutris nereis). Ecology 90:961-974

- Newsome SD, Bentall GB, Tinker MT, Oftedal OT and others (2010) Variation in $\delta^{13} \mathrm{C}$ and $\delta^{15} \mathrm{~N}$ diet-vibrissae trophic discrimination factors in a wild population of California sea otters. Ecol Appl 20:1744-1752

Pande A, MacDiarmid AB, Smith PJ, Davidson RJ and others (2008) Marine reserves increase the abundance and size of blue cod and rock lobster. Mar Ecol Prog Ser 366: $147-158$

Peterson BJ, Fry B (1987) Stable isotopes in ecosystem studies. Annu Rev Ecol Syst 18:293-320

Phillips DL, Gregg JW (2001) Uncertainty in source partitioning using stable isotopes. Oecologia 127:171-179

Polis GA, Strong DR (1996) Food web complexity and community dynamics. Am Nat 147:813-846

> Post D (2002) Using stable isotopes to estimate trophic position: models, methods, and assumptions. Ecology 83: $703-718$

Rodgers KL, Wing SR (2008) Spatial structure and movement of blue cod Parapercis colias in Doubtful Sound, New Zealand, inferred from $\delta^{13} \mathrm{C}$ and $\delta^{15} \mathrm{~N}$. Mar Ecol Prog Ser 359:239-248

Shears NT, Babcock RC, Salomon AK (2008) Contextdependent effects of fishing: variation in trophic cascades across environmental gradients. Ecol Appl 18:1860-1873

Suring E, Wing SR (2009) Isotopic turnover rate and fractionation in multiple tissues of red rock lobster (Jasus edwardsii) and blue cod (Parapercis colias): consequences for ecological studies. J Exp Mar Biol Ecol 370: 56-63

Tilman D, Downing JA (1994) Biodiversity and stability in grasslands. Nature 367:363-365

> Vander Zanden HB, Bjorndal KA, Reich KJ, Bolten AB (2010) Individual specialists in a generalist population: results from a long-term stable isotope series. Biol Lett 6:711-714

> Vanderklift MA, Ponsard S (2003) Sources of variation in consumer-diet $\delta^{15} \mathrm{~N}$ enrichment: a meta-analysis. Oecologia 136:169-182

> Wing SR (2009) Decadal-scale dynamics of sea urchin population networks in Fiordland, New Zealand are driven by juxtaposition of larval transport against benthic productivity gradients. Mar Ecol Prog Ser 378:125-134

> Wing SR, Leichter JJ (2011) Variation in environmental conditions in a subtidal prey refuge: effects of salinity stress, food availability and predation on mussels in a fjord system. Mar Ecol Prog Ser 422:201-210

Wing SR, Leichter JJ, Perrin C, Rutger SM, Bowman MH, Cornelisen CD (2007) Topographic shading and wave exposure influence morphology and ecophysiology of Ecklonia radiata (C. Agardh 1817) in Fiordland, New Zealand. Limnol Oceanogr 52:1853-1864

- Wing SR, McLeod RJ, Clark KL, Frew RD (2008) Plasticity in the diet of two echinoderm species across an ecotone: microbial recycling of forest litter and bottom-up forcing of population structure. Mar Ecol Prog Ser 360:115-123

> Witman JD, Grange KR (1998) Links between rain, salinity and predation in a rocky subtidal community. Ecology 79:2429-2447 